\title{
Research Paper: The Impact of Time-use Training on the Quality of Time Management in the Mothers of Children With Intellectual Disabilities
}

Sanaz Arzhangi ${ }^{1}$ (D), Meimanat Hosseini ${ }^{1 *}$ (D), Samaneh Hosseinzadeh² ${ }^{(1)}$, Mansoureh Zagheri Tafreshi ${ }^{1}$ (i)

1. Department of Community Health Nursing, Faculty of Nursing and Midwifery, Shahid Beheshti University of Medical Sciences, Tehran, Iran.

2. Department of Biostatistics,School of Rehabilitation Sciences, Social Welfare and Rehabilitation Sciences University, Tehran, Iran.

\begin{tabular}{|l|l|l|}
\hline $\begin{array}{l}\text { Use your device toscan } \\
\text { and read the article online }\end{array}$ & $\begin{array}{l}\text { Crttation: Arzhangi S, Hosseini M, Hosseinzadeh S, Zagheri Tafreshi M. The Impact of Time-use Training on the Quality of } \\
\text { Time Management in the Mothers of Children With Intellectual Disabilities. Iranian Rehabilitation Journal. 2020; 18(2):145- } \\
\text { 154. http://dx.doi.org/10.32598/irj.18.2.895.1 }\end{array}$ \\
\hline doi http://dx.doi.org/10.32598/irj.18.2.895.1
\end{tabular}

Article info:

Received: 05 May 2019

Accepted: 14 Jan 2020

Available Online: 01 Jun 2020

Keywords:

Intellectual Disability (ID), Education, Time management, Children with disability

\section{ABSTRACT}

Objectives: The present research aimed to determine the effect of time-use training on the quality of time management in the mothers of girls with Intellectual Disability (ID) attending special schools.

Methods: This was a quasi-experimental study with a control group design. In total, 80 mothers ( 40 mothers in the intervention group \& 40 mothers in the control group) of children with ID (age range: 6-13 years) were studied. The study participants were selected by cluster sampling method. The required data were collected using a demographic data questionnaire and the Mothers' Time Use Questionnaire (MTUQ). A time management training program was provided in a one-day workshop for the intervention group. The obtained data were analyzed in SPSS using Independent Samples t-test, Paired Samples t-test, and Chi-squared test.

Results: After the intervention period, the quality of time management of the mothers in the intervention group significantly increased, compared to the controls $(\mathrm{P}<0.05)$.

Discussion: The current research findings suggested that time-use training improved the quality of time management in the studied subjects. Therefore, educational interventions related to time management are recommended for the parents of children with ID. Besides, paying attention to this vulnerable group should be among nurses' responsibilities. 


\section{Highlights}

- Training improves the quality of time management.

- Effective training leads to satisfaction with time management.

\section{Plain Language Summary}

The mothers of children with Intellectual Disability (ID) spend more time taking care of their children, compared to the mothers of healthy children. However, providing care for children with ID should not cause any problems for the mothers. In training programs, mothers learn to improve their time management skills, increasing their daily life satisfaction. In this study, we designed an educational intervention for the mothers of children with ID in the intervention group. They participated in a workshop to learn how to manage their time with their children at home or in other settings. After the intervention, the intervention group, who participated in our training program, reported significant improvement and satisfaction in the quality of daily living activities. The findings revealed that the mothers of children with ID, who have adequate information about time management, have higher satisfaction with life.

\section{Introduction}

I

n managing children with mental and developmental disabilities or other chronic diseases, major attention must be paid to not only children and their problems, but also their families, as the major source of child support $[1,2]$. Intellectual

Disability (ID) affects the time use patterns of children. These patterns are interconnected in the family; thus, they could influence time management and life quality of other family members, especially mothers $[3,4]$.

Investigating time management could provide essential data about individuals' health and well-being. To understand the relationship between time management and health, it is necessary to describe individuals' experiences of daily living activities $[5,6]$. Significant attention has recently been paid to the integration of parental management in children's treatment plans [7, 8]. In Iran, mothers comprise $85 \%$ of the main caregivers of children with ID, which suggests the need for paying major attention to this population [9].

Home caregivers often feel not ready to provide care for their patients. This is because they have insufficient knowledge and are not supported by healthcare providers. Additionally, family caregivers are unfamiliar with the type or extent of care they should provide for these children, i.e. because of their inadequate knowledge and skills $[10,11]$. Furthermore, significant responsibility for community health nurses is to investigate, identify, and work with vulnerable families [12-14]. Accordingly, they could contribute to the care of children with disabilities and provide family consultation $[12,15,16]$.
However, only a few studies have concentrated on mothers' time management skills. In this regard, Gevir et al., (2006) compared time management among 120 mothers in 4 groups, as follows: 30 mothers of children with hyperactivity disorder; 29 mothers of children with mild to moderate ID; 30 mothers of children with a severe physical disability, and 31 mothers of healthy children [17]. Their findings suggested a significant difference in the hours of child care between the research groups. Moreover, the relevant results revealed that the mothers of children with disabilities spent more time taking care of their children, compared to the mothers of healthy children.

Furthermore, Ahmadi Kahjough compared the time use, leisure time, and quality of time management in 30 mothers of children with cerebral palsy and 37 healthy children's mothers. As a result, there was no significant difference in the mean scores of quality, importance, and leisure activities, manners of spending free time, and time management quality [18] between the study groups. However, there was a significant difference between the study groups in satisfaction and time management skills $(\mathrm{P}<0.05)$.

Studies overlooked investigating time management quality and satisfaction, and time use among the mothers of children with ID in Iran. Besides, the available findings are contradictory. Thus, the present research aimed to explore the effect of time-use training on the quality as well as satisfaction with time management in the mothers of girls with ID. In addition, the role of nurses, as individuals working with healthy individuals through preparing preventive healthcare and wellness 
information is significant. They could educate patients and family members about health conditions, provide emotional support, and so on. Therefore, they could support these families.

\section{Methods}

In this experimental study, all mothers of girls with ID, who were attending the public elementary schools of Tehran City, Iran, under the supervision of Special Education Department and Education Department, were recruited in 2015. All girls' schools were selected, i.e. because of gender segregation in Iranian schools and the need for having matched groups to compare the data. For sampling, the Western districts of Tehran were selected in consultation with the education authorities. The study samples were randomly selected by cluster sampling approach. For this purpose, each special school was considered as a cluster. Two schools were selected among the special schools (clusters) in the West of Tehran using the lottery sampling method by throwing a coin for determining the intervention and control groups. The reason for selecting this geographical area was the similarity in the economic status of samples.

The study inclusion criteria were as follows: having a nuclear family; having a child with ID aged 6-13 years; having an educable child with ID with an Intelligence Quotient (IQ) of 50-70; the absence of chronic physical or psychological problems in other children of the family; the absence of disabilities, such as blindness, deafness, and special diseases in the child; being the primary caregiver of the child in the family, and not having the responsibility of caring for another disabled person in the family (or relatives). Furthermore, the study exclusion criteria were family's unwillingness despite initial consent for participation in the educational program and non-completion of the questionnaires.

Initially, 96 mothers (48 in the intervention group and 48 in the control group) of children with ID were enrolled in the present study. The sample size was determined based on a study by Jalili et al. [19]. Considering the $95 \%$ confidence interval, $80 \%$ power, and minimum clinical difference in the score of stress between the stud groups ( $\mathrm{d} 2=4)$, the sample size was estimated as 48 individuals per group (Furmola 1):

$$
\text { 1. } n=\frac{\left(Z_{1-\alpha / 2}+Z_{1-\beta}\right)^{2} \delta^{2}}{d^{2}}
$$

Sixteen people ( $\mathrm{n}=8 /$ group) were excluded from the study according to the exclusion criteria. Finally, 80 subjects contributed to the current study. To collect the required data, two questionnaires were used, including the demographic data and mother's time use [17-19]. The demographic information questionnaire included 8 items, concerning the age of the child with ID, child's gender, child's birth, and educational grades, mother's age, mother's educational level, mother's occupational status, and the family's number of children.

Moreover, the Mothers' Time Use Questionnaire (MTUQ) was used to collect quantitative information about the use of time by the studied mothers. It evaluates the quality (how to perform an activity), importance, and pleasure of daily living activities. The MTUQ also grades the activities into 5 categories, as follows: Rest/sleep, child-related activities, leisure time, homework, and work/ occupation. Questions related to the quality, importance, and pleasure of activities are scored from one to 4, with lower scores reflecting the low quality of time management. Additionally, leisure time questions evaluate the individual's leisure time. Each person graded leisure activities from one (no activity) to 4 (always active), with lower scores indicating less engagement in leisure activities.

Questions related to time management quality consider the simultaneous execution of tasks and the lack of time for some activities due to the high level of engagement. The questions are scored from one (always) to 4 (never), with lower scores suggesting the low quality of time management. Finally, mothers scored their satisfaction with time management skills, with higher scores signifying greater satisfaction (score range: 1-4) [17-19].

The Mothers' Time Use Questionnaire (MTUQ) (Gevir et al., 2006) was first translated into Persian by Ahmadi Kahjough (2011) in Iran; its validity was reported to be adequate $[17,18]$. In the present study, the validity of this questionnaire was approved by measuring the Content Validity Index (CVI) (relevance $=0.92$, clarity $=0.88$, $\&$ simplicity $=0.88$ ). Moreover, the MTUQ's reliability was determined based on the internal consistency method (Cronbach's alpha coefficient) and the test-retest approach. To evaluate internal consistency, the questionnaire was presented to 15 eligible mothers (not the research samples). The internal consistency (Cronbach's alpha coefficient) of the MTUQ was also measured to be $\alpha=0.86$. In addition, to determine the stability of the questionnaire, it was completed by 15 qualified mothers (not the research participants) within two weeks. The correlation coefficient between the two tests was calculated as $\mathrm{r}=0.98$.

The questionnaires were distributed among the studied mothers after obtaining approval from the Ethics Com- 


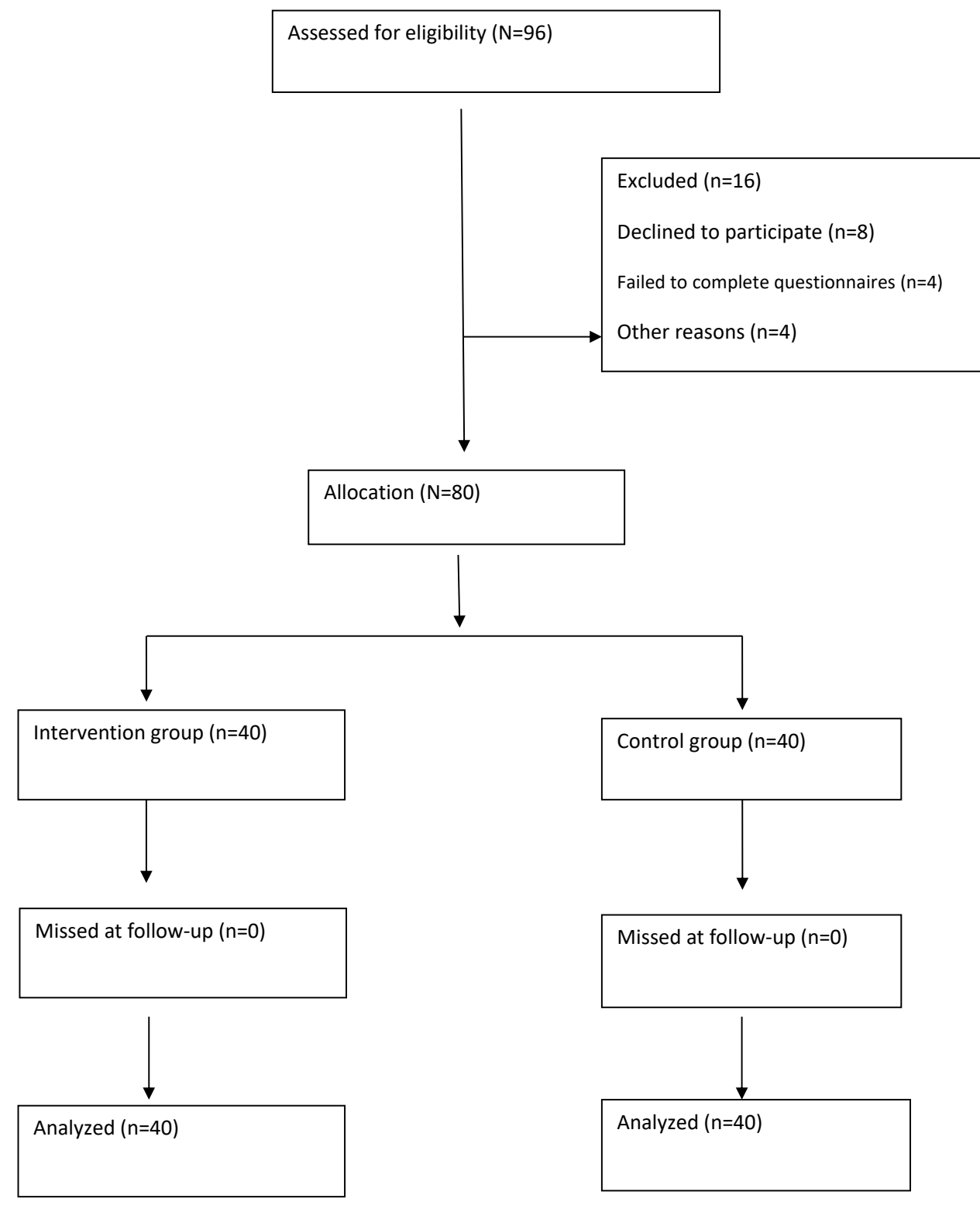

Figure 1. The flow-chart of the study

Пranian Rehabilitation \ournal

mittee of Faculty of Nursing and Midwifery (Code: IR.SBMU.PHNM.1394.201) and collecting written informed consent forms from the explored samples. After obtaining approval from the Educational Deputy of Faculty of Nursing and Midwifery, several special schools were introduced by the responsible authorities for recruiting the mothers of girls with ID from each educational district.

For data collection, the researcher first randomly selected two special schools from one district. Then, we randomly assigned the schools to the intervention and control groups. After selecting the clusters, the samples were recruited according to the inclusion criteria using a purposive sampling method and were invited to the school. The intervention and control groups were of two separate schools. In each school, 60 families met the study inclusion criteria. Forty-eight families were selected by assigning numbers and using the table of random numbers. After explaining the study objectives to the samples, they provided an informed consent form to participate in the study. Next, the demographic data questionnaire and MTUQ were presented to the mothers of both study groups.

In the intervention group, after collecting the survey scales, a six-hour workshop was held regarding the optimal use of time using lectures, question, and answer, educational slideshows, along with educational pamphlets 
concerning the research topic. Subsequently, the internalization of training continued for 6 weeks by providing the study subjects with educational pamphlets (e.g. key points about time management) to remind them of the relevant principles and concepts. At the follow-up stage, the MTUQ was re-completed by the intervention group. Furthermore, the study questionnaires were completed again by the control group after 6 weeks. Finally, the acquired data were analyzed in SPSS using Independent Samples t-test, Paired Samples t-test, and Chi-squared test.

\section{Results}

In the present study, 80 mothers of girls with ID were studied (Figure 1). The demographic findings indicated that both study groups were similar in terms of age, edu- cational level, the number of children, and occupational status $(\mathrm{P}>0.05)$ (Table $1 \&$ Table 2$)$.

Before the intervention, the mean score of time use was 2.95-3.16 in the intervention group and 2.99-3.29 in the control group. On the other hand, after the intervention, the score of time use was 3.26-3.63 in the test group and 3.02-3.28 in the control group. As per Table 3, examining the qualitative aspects of time use (quality, importance, \& pleasure) revealed that after training, the intervention group performed their activities with significantly higher quality, compared to the controls $(\mathrm{P}=0.0001)$. They were also more careful about their caring activities $(\mathrm{P}=0.004)$ and enjoyed them more than the controls $(\mathrm{P}=0.007)$ (Table 3$)$.

After the training, among the 5 areas of activity, the intervention group performed home activities with high

Table 1. The age of the investigated mothers and their children in the intervention and control groups

\begin{tabular}{|c|c|c|c|}
\hline \multirow{3}{*}{ Characteristics } & \multicolumn{2}{|c|}{ Groups } & \multirow{3}{*}{$\mathbf{P}$ a } \\
\hline & \multicolumn{2}{|c|}{ Mean士SD } & \\
\hline & Intervention & Control & \\
\hline Mothers' age (y) & $40.40 \pm 7.17$ & $39.85 \pm 9.97$ & 0.778 \\
\hline Children's age (y) & $11.05 \pm 2.17$ & $9.93 \pm 3.49$ & 0.088 \\
\hline
\end{tabular}

${ }^{a}$ Chi-squared test, or Independent Samples t-test.

Iranian Rehabilitation Dournal

Table 2. The demographic characteristics of the intervention and control groups

\begin{tabular}{|c|c|c|c|c|}
\hline \multirow{2}{*}{\multicolumn{2}{|c|}{ Characteristic }} & \multicolumn{2}{|c|}{ Groups } & \multirow{3}{*}{$\mathbf{P a}^{a}$} \\
\hline & & \multicolumn{2}{|c|}{ No. (\%) } & \\
\hline & & Intervention & Control & \\
\hline \multirow{5}{*}{ Educational level } & Elementary & $2(5)$ & $9(22.5)$ & \multirow{5}{*}{$0.10 s$} \\
\hline & Junior level & $6(15)$ & 7 (17.5) & \\
\hline & & & & \\
\hline & High school & $23(57.5)$ & $19(47.5)$ & \\
\hline & Academics & $9(22.5)$ & $5(12.5)$ & \\
\hline \multirow{3}{*}{$\begin{array}{l}\text { The number of } \\
\text { children }\end{array}$} & One & $17(42.5)$ & $13(32.5)$ & \multirow{3}{*}{0.513} \\
\hline & Two \& Three & $15(37.5)$ & 15 (37.5) & \\
\hline & $\begin{array}{l}\text { More than } \\
\text { three }\end{array}$ & $8(20)$ & $12(30)$ & \\
\hline \multirow{3}{*}{ Occupational status } & Housewife & $28(70)$ & $30(75)$ & \multirow{3}{*}{0.747} \\
\hline & Employed & $11(27.5)$ & $10(25)$ & \\
\hline & Retired & $1(2)$ & $0(0)$ & \\
\hline
\end{tabular}

${ }^{a}$ Chi-squared test, or Independent Samples t-test

Mranian Rehabilitation Journa 
Table 3. The quality aspects of time use in the study groups

\begin{tabular}{|c|c|c|c|c|}
\hline \multirow{3}{*}{ Characteristic } & \multirow{3}{*}{ Group } & \multicolumn{2}{|c|}{ Mean士SD } & \multirow{3}{*}{$\mathbf{P}^{\mathrm{a}}$} \\
\hline & & \multicolumn{2}{|c|}{ Time } & \\
\hline & & Pre-test & Post-test & \\
\hline \multirow{3}{*}{ Quality } & Intervention & $2.95 \pm 0.45$ & $3.63 \pm 0.49$ & 0.0001 \\
\hline & & & & \\
\hline & Control & $2.99 \pm 0.43$ & $3.02 \pm 0.42$ & 0.503 \\
\hline \multirow{2}{*}{ Importance } & Intervention & $3.16 \pm 0.44$ & $3.48 \pm 0.39$ & 0.004 \\
\hline & Control & $3.29 \pm 0.32$ & $3.28 \pm 0.38$ & 0.849 \\
\hline \multirow{2}{*}{ Enjoyment } & Intervention & $2.98 \pm 0.52$ & $3.26 \pm 0.37$ & 0.007 \\
\hline & Control & $3.04 \pm 0.44$ & $3.11 \pm 0.48$ & 0.579 \\
\hline
\end{tabular}

${ }^{a}$ Chi-squared test, or Independent Samples t-test

Пranian Rehabilitation Journal

Table 4. Between- and within-group comparisons regarding the mean scores of satisfaction with time management

\begin{tabular}{|c|c|c|c|c|}
\hline \multirow{3}{*}{ Group } & \multicolumn{3}{|c|}{ Mean士SD/ No.(\%) } & \multirow{3}{*}{$\mathbf{P}^{\mathbf{a}}$} \\
\hline & \multicolumn{2}{|c|}{ Time } & \multirow{2}{*}{ Difference } & \\
\hline & Pre-test & Post-test & & \\
\hline Intervention & $2.95 \pm 0.74$ & $3.43 \pm 0.63$ & $0.58 \pm 0.63$ & 0.0001 \\
\hline Control & $3.18 \pm 0.38$ & $3.15 \pm 0.48$ & $0.03 \pm 0.48$ & 0.799 \\
\hline $\mathrm{P}^{\mathrm{b}}$ & 0.084 & 0.028 & 0.000 & - \\
\hline
\end{tabular}

Iranian Rehabilitation \ournal

${ }^{\text {a }}$ Paired Samples t-test; ${ }^{\mathrm{b}}$ Independent Samples t-test

Table 5. Between- and within-group comparisons regarding the mean scores of time management quality

\begin{tabular}{|c|c|c|c|c|}
\hline \multirow{3}{*}{ Group } & \multicolumn{3}{|c|}{ Mean士SD/ No.(\%) } & \multirow{3}{*}{$\mathbf{P}^{\mathbf{a}}$} \\
\hline & \multicolumn{2}{|c|}{ Time } & \multirow{2}{*}{ Difference } & \\
\hline & Pre-test & Post-test & & \\
\hline Intervention & $42.10 \pm 6.46$ & $46.80 \pm 6.98$ & $4.70 \pm 5.44$ & 0.003 \\
\hline Control & $42.53 \pm 6.81$ & $42.38 \pm 4.14$ & $0.15 \pm 6.81$ & 0.921 \\
\hline $\mathrm{P}^{\mathrm{b}}$ & 0.773 & 0.001 & 0.001 & - \\
\hline
\end{tabular}

${ }^{\text {a }}$ Paired Samples t-test; ${ }^{\mathrm{b}}$ Independent Samples t-test

quality and enjoyed their time. Among the 5 areas of activity, the studied mothers of children with ID were very careful about their children. Besides, care-related measures were more important to them than other activities. The difference in the mothers' satisfaction with time management skills was significant in the interven- tion group before and after the intervention $(\mathrm{P}=0.0001)$. The findings demonstrated a significant difference between satisfaction levels and time management skills in the intervention group before and after the intervention $(\mathrm{P}<0.05)$. However, the control group presented no significant difference in this area (Table 4). Moreover, 
our results indicated a significant difference between the groups after the intervention $(\mathrm{P}>0.05)$.

The obtained data suggested that the total score of time management quality significantly differed between the pre-test and post-test phases in the experimental group $(\mathrm{P}<0.05)$. However, the control group demonstrated no significant difference in this regard (Table 5). In other words, training was effective in improving time management quality in the intervention group.

\section{Discussion}

The present study findings suggested a significant ant difference in the total score of time management quality in the test group before and after the intervention. Moreover, there was a significant difference in the total score of satisfaction and time management after the training in the intervention group; however, no significant difference was observed in the control group in this respect.

Based on the literature, studied disregarded exploring time management quality and satisfaction after providing time use training. The results of pre-training in the present study are consistent with those of comparative studies. For example, Gevir et al. compared the use of time between the mothers of children with disabilities and those of healthy children. Mohammad Pour (2014) also compared the use of time management in the mothers of children with autism and those of healthy children $[17,20,21]$.

Based on the achieved results, the mothers of children with ID spent more time on child care, compared with the mothers of healthy children. Although no significant difference was observed between other activity areas among the study groups, the mothers of children with ID reported less time allocated for sleep, working, as well as social activities. These data highlighted an imbalance in time spent on performing activities in the mothers of children with ID. Furthermore, the mothers of children with ID spent more time on childcare; these results are consistent with those of other relevant investigations $[17,22,23]$.

Investigating the qualitative aspects of time use after training signified a significant difference in the quality, importance, and pleasure of activities between the study groups; these data re inconsistent with those of Gevir and Ahmadi Kahjough [17, 18]. Such a data inconsistency may be attributed to the differences in the educational interventions and descriptive design of the mentioned studies.

Furthermore, the present study results revealed that the mean score of time management quality after training was higher in the intervention group, compared to the scores reported by Ahmadi Kahjough [18]; this finding may be attributed to the educational intervention used in the present study. Training improved the quality of time management in the intervention group by providing a set of skills for better control and use of time (time management) $[20,22,24]$.

Some study limitations included the lack of comparative data, the inadequate cooperation of some mothers due to their unwillingness to provide information, and the missing of samples (17\%); these restrictions could affect the generalizability of our findings. According to the obtained results, the time management of mothers living with their spouse needs to be compared with that of the mothers who live apart from their spouse. Investigating the effects of a child's age and severity of disorder on the pattern of mothers' time use is also suggested. Moreover, it is recommended that similar studies be conducted in different populations, given the importance of ethnicity and culture. Since a one-week note provides more detailed information about some areas, such as social participation and the diversity of leisure activities, further studies in this area seem beneficial. Nurses have direct contact with patients and other healthcare staff; therefore, they could advise families or introduce them to different treatments.

\section{Conclusion}

The purpose of the training provided in the present study was to highlight the importance of effective interventional methods in understanding the time management needs of mothers and their satisfaction with engagement in daily living activities. In addition, mothers' proper functioning is related to their appropriate use of time. Nurses could also help mothers by encouraging changes in family members to improve their adaptation to the disability and chronic consequences of the disease. The presented research determined the effect of time-use training in the mothers of children with ID, attending special schools. The research hypotheses were established, suggesting that time-use education increases the quality of time management.

\section{Ethical Considerations}

\section{Compliance with ethical guidelines}

This clinical trial was approved by the Ethics Committee of Shahid Beheshti University of Medical Sciences (Code: IR.SBMU.PHNM.1394.201.). Also this study was registered in the Iranian Registry of Clinical Trials (Code: IRCT20180924041110N1). Written informed 
consent forms were obtained from all research participants before enrollment in the study.

Funding

This research did not receive any grant from funding agencies in the public, commercial, or non-profit sectors.

\section{Authors' contributions}

All authors contributed in preparing the current research.

\section{Conflict of interest}

The authors declared no conflicts of interest.

\section{Acknowledgments}

The authors express their gratitude to the Special Education Office of Tehran, as well as the studied schools and participating families.

\section{References}

[1] Luther BL, Christian BJ. Parent perceptions of health promotion for school-age children with spina bifida. Journal for Specialists in Pediatric Nursing. 2017; 22(1):e12168. [DOI:10.1111/jspn.12168] [PMID]

[2] Cerqueira MMF, de Oliveira Alves R, Aguiar MGG. [Experiences in the therapeutic itineraries of mothers of children with intellectual disabilities (Portuguese, English)]. Ciência \& Saúde Coletiva. 2016; 21(10):3223-32. [DOI:10.1590/1413812320152110.17242016] [PMID]

[3] Janeslätt G, Kottorp A, Granlund M. Evaluating intervention using time aids in children with disabilities. Scandinavian Journal of Occupational Therapy. 2014; 21(3):181-90. [DOI:10. 3109/11038128.2013.870225] [PMID]

[4] Janeslätt G, Granlund M, Kottorp A. Measurement of time processing ability and daily time management in children with disabilities. Disability and Health Journal. 2009; 2(1):15-9. [DOI:10.1016/j.dhjo.2008.09.002] [PMID]

[5] Jonas DE, Ibuka Y, Russell LB. How much time do adults spend on health-related self-care? Results from the American time use survey. Journal of the American Board of Family Medicine. 2011; 24(4):380-90. [DOI:10.3122/jabfm.2011.04.100260] [PMID]

[6] McCann D, Bull R, Winzenberg T. The daily patterns of time use for parents of children with complex needs: A systematic review. Journal of Child Health Care. 2012; 16(1):26-52 [DOI:10.1177/1367493511420186] [PMID]

[7] Schenker R, Parush S, Rosenbaum P, Rigbi A, Yochman A. Is a family-centred initiative a family-centred service? A case of a Conductive Education setting for children with cerebral palsy. Child: Care, Health and Development. 2016; 42(6):909-17 [DOI:10.1111/cch.12354] [PMID]

[8] Sawyer MG, Bittman M, La Greca AM, Crettenden AD, Borojevic N, Raghavendra P, et al. Time demands of caring for children with cerebral palsy: What are the implications for maternal mental health? Developmental Medicine \& Child Neurology. 2011; 53(4):338-43. [DOI:10.1111/j.14698749.2010.03848.x] [PMID]

[9] Koohsali M, Mirzamani M, Karimlo M, Mirzamani M. [Comparison of social adjustment in mothers with and without of educable mentally retarded daughter (Persian)]. International Journal of Behavioral Sciences. 2008; 2(2):165-72. http://www. behavsci.ir/article_67589.html

[10] Yıldırım A, Hacıhasanoğlu Aşılar R, Karakurt P. Effects of a nursing intervention program on the depression and perception of family functioning of mothers with intellectually disabled children. Journal of Clinical Nursing. 2013; 22(1-2):251-61. [DOI:10.1111/j.1365-2702.2012.04280.x] [PMID]

[11] Cenk SC, Muslu GK, Sarlak D. The effectiveness of structured supported education programs for families with intellectually disabled children: The example of Turkey. Archives of Psychiatric Nursing. 2016; 30(6):704-9. [DOI:10.1016/j.apnu.2016.05.008] [PMID]

[12] Huang YP, Kellett U, St John W. Being concerned: Caregiving for Taiwanese mothers of a child with cerebral palsy. Journal of Clinical Nursing. 2012; 21(1-2):189-97. [DOI:10.1111/j.13652702.2011.03741.x] [PMID]

[13] Muntean A, Tomita M, Ungureanu R. The role of the community nurse in promoting health and human dignity-narrative review article. Iranian Journal of Public Health. 2013; 42(10):107784. [PMID] [PMCID]

[14] World Health Organisation. A framework for community health nursing education. New Delhi: World Health Organisation; 2010. https:/ /apps.who.int/iris/handle/10665/204726

[15] Claessens BJC, van Eerde W, Rutte CG, Roe RA. A review of the time management literature. Personnel Review. 2007; 36(2):255-76. [DOI:10.1108/00483480710726136]

[16] Jachimiec JA, Obrecht J, Kavanaugh K. Interactions between parents of technology-dependent children and providers: An integrative review. Home Healthcare Now. 2015; 33(3):155-66. [DOI:10.1097/NHH.0000000000000205] [PMID]

[17] Gevir D, Goldstand S, Weintraub N, Parush Sh. A comparison of time use between mothers of children with and without disabilities. OTJR: Occupation, Participation and Health. 2006; 26(3):117-27. [DOI:10.1177/153944920602600305]

[18] Ahmadi Kahjugh M, Rassafiani M, Hoseini SA, Sourtiji H. [Comparing the patterns of time use and satisfaction of time management among mothers of children with cerebral palsy and mothers of healthy children (Persian)]. Journal of Research in Rehabilitation Sciences. 2012; 8(1):10-7. http://jrrs.mui.ac.ir/ index.php/jrrs/article/view/185

[19] Jalili N, Gudarzy M, Rassafiani M, Farzi M .[The assessment of effectiveness of handling training program on knowledge of mothers regarding proper care of children with cerebral palsy (Persian)]. Journal of Research in Rehabilitation Sciences. 2012; 8(3):502-10. http://jrrs.mui.ac.ir/index.php/jrrs/article/ view/560 
[20] Mohammadpour M , Rassafiani M, Ahmadi Kahjugh M , Behnia F, Haghgoo H, Biglarian A. [Comparing time use in mothers with autistic child and mothers with healthy child (Persian)]. Journal of Research in Rehabilitation Sciences. 2014; 10(1):182-92. http://jrrs.mui.ac.ir/index.php/jrrs/article/view/1304

[21] Koegel L, Matos-Freden R, Lang R, Koegel R. Interventions for children with autism spectrum disorders in inclusive school settings. Cognitive and Behavioral Practice. 2012; 19(3):401-12. [DOI:10.1016/j.cbpra.2010.11.003]

[22] Behnia F, Rassafiani M, Nakhai S, Mohammadpour M, Ahmadi Kahjoogh M. Time use of mothers of children with an autism spectrum disorder: A comparative study. Iranian Rehabilitation Journal. 2017; 15(1):49-56. [DOI:10.18869/nrip. irj.15.1.49]

[23] Crowe TK, Michael HJ. Time use of mothers with adolescents: A lasting impact of a child's disability. OTJR: Occupation, Participation and Health. 2011; 31(3):118-26. [DOI:10.3928/15394492-20100722-01]

[24] Armstrong M. Armstrong's handbook of strategic human resource management. $6^{\text {th }}$ ed. London: Kogan Page; 2011. https:/ / www.koganpage.com/product/armstrong-s-handbook-ofstrategic-human-resource-management-9780749476823 
This Page Intentionally Left Blank 